\title{
Cultura Livre: Colaboração e Compartilhamento
}

\author{
Edvaldo de Aguiar Portela Moita \\ Aluno do curso de Direito da FA7. \\ edvaldo_apm@hotmail.com
}

Sumário: Introdução; 1. A tentativa de adaptação de um modelo antigo sob perspectivas novas; 2. Um novo modelo de paradigma de produção: o modelo colaborativo; 3. O licenciamento público de obras intelectuais: o Creative Commons; 3.1 Alguns exemplos de modelos colaborativos. Conclusão. Referências.

Resumo: A propriedade intelectual não mais comporta os avanços sociais provocados pela internet e pela tecnologia digital, os quais são responsáveis pelo desenvolvimento de novas relações sociais. Como alternativa ao regime tradicional de direitos autorais, surgem movimentos que procuram uma maior socialização do conhecimento. Assim, a partir da obra Direito, tecnologia e cultura, do autor Ronaldo Lemos, é que o presente trabalho pretende apresentar alguns esboços desses movimentos, mormente o Creative Commons, defendendo os benefícios de uma mitigação da propriedade intelectual.

Palavras-chave: Informação. Direitos Autorais. Cultura Livre. Creative Commons.

\section{INTRODUÇÃO}

Uma das características marcantes do mundo atual é a velocidade com que as informações ${ }^{1}$ são transmitidas. A internet acabou por diminuir drasticamente as fronteiras físicas entre os quatro cantos do mundo, não só propiciando a troca instantânea de informação, como desenvolvendo novos processos de relações sociais.

Conjuntamente, a tecnologia digital passou a desempenhar um papel fundamental na convivência humana, em que, cada vez mais, sua utilização se apresenta

\footnotetext{
1 Aqui o termo 'informação' será tratado num sentido mais genérico, não só englobando um conjunto de conhecimentos reunidos sobre determinado assunto ou pessoa como, também, uma mensagem suscetível de ser tratada pelos meios informáticos ou o conteúdo dessa mensagem.
} 
como essencial para o funcionamento da sociedade como um todo. Pode-se notar isso desde a necessidade de uso pessoal de um computador até a utilização de bancos de dados no próprio aparato estatal.

No entanto, é necessário destacar alguns aspectos jurídicos desse contexto que passam a se inter-relacionar tanto com a tecnologia digital como com a internet, os quais se submetem ao regime de propriedade intelectual, lidando "com os direitos de propriedade das coisas intangíveis oriundas das inovações e criações da mente" (Ministério da Cultura, 2009, on-line), com o finco de proteger todas essas criações, dando aos seus titulares direitos econômicos sobre produtos e serviços que incorporam tais criações.

A propriedade intelectual pode ser subdividida em três ramos de proteção: propriedade industrial, cultivares e direito autoral. Sendo este "os direitos que o criador de obra intelectual exerce sobre suas criações" (Ministério da Cultura, 2009, on-line) conjuntamente com os direitos a ele conexos (os do artista, do produtor de fonogramas, dos organismos de radiodifusão), o presente trabalho se propõe a analisar, revelando a insuficiência dos regimes normativos atuais, algumas linhas de fuga encontradas pela sociedade para se esgueirar dessa proteção jurídica, a qual não mais comporta os fatos sociais contemporâneos.

\section{ATENT ATIVADE ADAPTAÇÃO DE UM MODELO ANTIGO DIANTE DE FATOSNOVOS}

A partir do conceito de direito autoral explicitado acima, tem-se por obra intelectual a "criação do espírito, expressa por qualquer meio ou fixada em qualquer suporte, tangível ou intangível" (Ministério da Cultura, 2009, on-line). No Brasil, a legislação, para fins de regulação, divide as obras intelectuais em programas de computador, cuja lei específica é a 9.609/98, e as literárias, artísticas e científicas, protegidas pela lei 9.610/98.

Parte dos problemas enfrentados hoje com a violação dos direitos autorais, também conhecidos pelo termo copyright, remete ao contexto internacional dessa década de 90, a qual foi marcada pelo "boom" da expansão da rede mundial de computadores, o que viria a aumentar não somente a velocidade de envio de informações pelo mundo mas também a facilidade na cópia, modificação e transferência de conteúdos, demonstrando em parte a incapacidade dos dispositivos normativos de conter essa novidade. Como menciona Lemos (2005, p. 31-32):

\footnotetext{
Pregava-se, no começo da década de 1990, que era impossível regular a internet pelos meios jurídicos tradicionais. Naquele momento, tal crença permitiu o florescimento da rede de forma nunca sequer imaginada, fazendo com que, em 1995, ela fosse o meio mais livre e democrático, bem como pluralista, de circulação de informações. Ao longo de um curto período de tempo, tal crença cedeu lugar à sua antítese: a hipertrofia de formas tradicionais de proteção à propriedade intelectual como reação à suposta "anarquia" da internet. O que era livre passou a ser severamente controlado.
} 
O temor precoce por uma anarquia da rede acabou por resultar em medidas legislativas excessivamente restritivas, pendendo-se para a proteção dos direitos autorais sem que se sopesassem devidamente todas as outras problemáticas envolvidas, tais como o direito à informação e a liberdade de expressão. Um exemplo dessas medidas é o Digital M illenium Copyright Act(DMCA), a qual foi adotada pelos Estados Unidos em outubro de 1998 como uma tentativa de fortalecer os direitos autorais. O DMCA acabou por criminalizar a produção e difusão de tecnologias destinados a contornar o acesso a obras protegidas pelo copyright, inclusive os atos que tenham por finalidade burlar um eventual controle de acesso, ainda que não tenha havido violação dos direitos autorais em si, majorando, ainda, as penas por violação desses direitos na internet ${ }^{2}$ (Wikipédia, 2001, on-line).

No Brasil, as leis 9.609/98 e 9.610/98, criadas dentro mesmo contexto do DMCA, sobrelevando os direitos autorais, não conseguiram tratar de todas as questões envolvidas, deixando certos aspectos de lado. Aponta Lemos (2005, p. 96-97):

\begin{abstract}
Como resultado disso, questões cruciais - como, por exemplo, a responsabilidade dos provedores de acesso à internet, a privacidade, os direitos de uso legítimos de informações na internet, a responsabilidade dos prestadores de serviços on-line, os incentivos à cultura nacional, a criação de um regime suficientemente diferenciado para a proteção do software que o torne distinto do modelo de proteção do direito autoral atualmente empregado e, sobretudo, a proteção aos bens intelectuais e ao patrimônio cultural local em face dos avanços e das pressões cada vez maiores exercidos no âmbito da globalização - ficaram de fora dos textos legais que naturalmente as abrigariam.
\end{abstract}

A adoção intempestiva dessas restrições contribuiu para a produção de um descompasso entre os textos normativos e a realidade que começaria a surgir, resultando num ambiente em que a informação passaria a se difundir, seja ao largo das regulamentações existentes, incluindo-se os mais diversos tipos de burla aos direitos autorais, como gravação de GDs e DVDs, cópias não autorizadas de livros, downloads de filmes, utilização de softwares piratas; seja através da criação de novos modelos de produção, emergindo aqui a ideia de uma cultura livre cujas finalidades são a colaboração e compartilhamento.

\title{
2 UM NOVO PARADIGMADE PRODUÇÃO: O MODELO COLABORATIVO
}

É de se notar algumas alternativas buscadas pela sociedade ao modelo tradicional de propriedade intelectual. Vê-se aqui a insurgência de vários movimentos sociais para

\footnotetext{
2 Do original: It criminalizes production and dissemination of technology, devices, or services intended to circumvent measures $[\ldots .$.$] that control access to copyrighted works. It also criminalizes the act of cir-$ cumventing an access control, whether or not there is actual infringement of copyright itself. In addition, the DMCA heightens the penalties for copyright infringement on the Internet. (tradução livre do autor).
} 
além desse regime de direitos autorais. O projeto pioneiro se deu com a criação do Linux, um sistema operacional de computadores cuja inovação estava na abertura do seu código-fonte ${ }^{3}$, permitindo que qualquer usuário pudesse modificar o seu conteúdo (Linux Online, 1994, online). Desse modo, inaugurou-se uma nova forma de produção de obras intelectuais, baseada na descentralização e cooperação aberta.

A criação do Linux deu início ao movimento do Software Livre (F ree Software). Como se vê em Lemos (2005, p. 71-72):

\begin{abstract}
O movimento do software livre é produto da subversão das tradicionais ideias [sic] de propriedade com relação aos "bens intelectuais". Originou-se da insatisfação relativa ao regime tradicional de direito autoral quando aplicado ao software, na medida em que ele impedia as possibilidades de se atender a objetivos que fossem além daqueles puramente econômicos. Nesse sentido, o movimento do software livre teve como escopo transformar a proteção da propriedade intelectual para criar bens intelectuais abertos, amplamente acessíveis tanto com relação ao uso, quanto à possibilidade de inovação e modificação, não só do ponto de vista econômico, como também do ponto de vista cognitivo.
\end{abstract}

A novidade se voltava para a criação de programas de computadores a partir da cooperação de várias pessoas, independentemente da ideia de empresa ou mercado, sendo possível tanto o acesso ao código-fonte do software quanto a sua modificação e, inclusive, a criação de trabalhos derivados a partir dele. É daí que surge o copyleft como a prática de utilizar a lei de direitos autorais para eliminar as restrições à distribuição de cópias e versões modificadas de um trabalho para os outros e exigir que as mesmas liberdades sejam preservada nas versões modificadas ${ }^{4}$ (Wikipédia, 2001, online). O termo é utilizado em contraposição ao copyright, pois se utiliza deste para sua fundamentação. Assim, é a partir das prerrogativas de autor dadas pelo direito autoral que as obras regidas pelo copyleft têm permissão para serem livremente redistribuídas e copiadas, desde que sempre permaneçam com o caráter de livres.

A partir do movimento do software livre, uma esperança de livre acesso à informação estaria configurada, tendo-se uma nova perspectiva quanto aos moldes tradicionais da propriedade intelectual. Uma possibilidade de solução frente à incapacidade do direito para com a realidade, dando início a um novo paradigma de produção de obras intelectuais: um modelo colaborativo.

3 Pode-se entender como código-fonte um sistema de símbolos utilizados em um determinado programa de computador para que seja possível sua alteração.

${ }^{4}$ Do original: Copyleft is a play on the w ord copyright to describe the practice of using copyright law to remove restrictions on distributing copies and modified versions of a w ork for others and requi ring that the same freedoms be preserved in modified versions (tradução livre do autor). 
O objetivo dessa nova forma de organização das forças de produção, somente possível a partir da internet e da tecnologia digital, é a criação de obras intelectuais abertas, com finalidades, principalmente, cognitivas. A inovação está na possibilidade de se ter a participação de inúmeros autores numa mesma obra, sem ter a preocupação de quem será o seu detentor, já que ela estará disponível para todos. Assim, os autores são movidos por incentivos não econômicos, como divertimento, lazer, novas experiências, sensação de retribuição de conhecimento à sociedade. À medida que a colaboração de cada um aumenta, o projeto apresenta grandes chances de se tornar mais complexo e funcional. Inúmeras são as possibilidades de aplicação, não comportando somente softwares como também músicas, documentos, livros, vídeos. Todo e qualquer tipo de criação suscetível de ser digitalizada, daí em diante poderá ser regida pelo regime de copyleft.

\section{UMA FRENTE DE LUTAPOR UMA CULTURA LIVRE: O CREATIVE COMMONS}

Sob o lema "É fácil quando você não precisa de intermediários", o C reative C ommons é uma instituição criada em 2001 nos Estados Unidos por Lawrence Lessig, com o objetivo de desenvolver licenças que visam à disponibilidade e ao compartilhamento de obras intelectuais (Creative Commons, 2001, on-line). Ao contrário dos direitos autorais, os quais funcionam a partir da máxima "todos os direitos reservados" (all rights reserved), as licenças Creative Commons remetem à ideia de "alguns direitos reservados" (some rights reserved).

À frente do modelo colaborativo, pode-se dizer que o Creative Commons constitui parte do movimento denominado cultura livre, cujo principal objetivo é a socialização do conhecimento com a livre propagação da informação, aumentando, consequentemente, o domínio público. No entanto, as autorizações criadas pelo Creative Commons, as quais são caracterizadas pelo regime de copyleft, não inserem a obra no domínio público e sim criam um regime alternativo ao da propriedade intelectual tradicional, em que tanto se protege os direitos do autor como podem permitir o uso, modificação e distribuição da sua obra, a depender da licença utilizada. Com isso, objetivam a propagação de conteúdos livres, facilitando o compartilhamento entre os seus usuários.

Nota-se que esse modelo apresenta todo um aparato jurídico criado fora dos organismos legiferantes convencionais, não havendo intervenção estatal em sua organização. Os agentes de transformação são os próprios indivíduos, os quais, utilizando-se dos direitos autorais, criam uma maneira diferente de utilizá-los. Demonstra Lemos (2005, p. 83):

Essas licenças criam uma alternativa ao direito da propriedade intelectual tradicional, fundada de baixo para cima, isto é, em vez de criadas por lei, elas se fundamentam no exercício das prerrogativas que cada indivíduo tem, como autor, de permitir o acesso às suas obras e a seus trabalhos, autorizando que outros possam utilizá-los e criar sobre eles. 
Desse modo, o Creative Commons cria licenças-modelo para que o autor possa escolher, conforme sua conveniência, uma dentre a gama de opções existentes. As autorizações podem ser concedidas para qualquer tipo de obra intelectual, desde um livro até a criação de um carro, como demonstrarão alguns exemplos no tópico 3.1.

Disponíveis em mais de quarenta jurisdições, essas licenças-modelo, cada vez mais, vão se espalhando pelo mundo, apresentando novas formas de criação de obras intelectuais. Sendo permitido ao autor que o mesmo escolha mais de uma licença e, até mesmo, combinar as existentes, da maneira que melhor lhe convir, elas podem ser condicionadas a alguns termos dentre outros, sendo os principais:

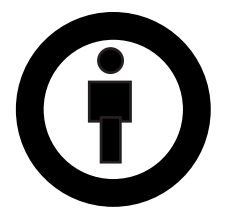

Atribuição (Attribution) (abreviatura: by)

Sendo a menos restritiva, o autor autoriza a livre distribuição, exibição, execução e, inclusive, a criação de obras derivadas, desde que sempre sejam atribuídos os devidos créditos ao autor original.

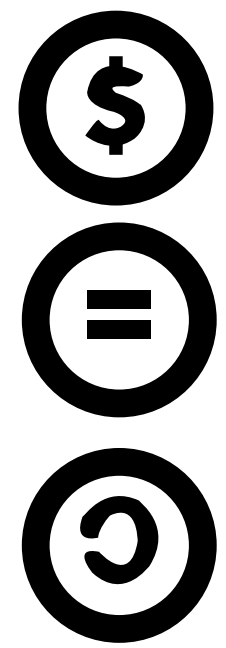

Vedados Usos Comerciais (N on-C ommercial) (abreviatura: nc)

Através dessa licença, o autor autoriza a livre distribuição, exibição, execução e, inclusive, a criação de obras derivadas, desde que seja para fins não comerciais.

Não a obras derivadas (N o D erivative W orks) (abreviatura: nd)

O autor autoriza a livre distribuição, exibição e execução da obra, mas veda a criação de qualquer obra derivada.

Compartilhamento pela mesma licença (Share Alike) (abreviatura: sa) Através dessa licença, o autor autoriza a livre distribuição, exibição, execução e, inclusive, a criação de obras derivadas, desde que seja para fins não comerciais.

No Brasil, a adaptação desses termos e licenças é feita em parceria pela Escola de Direito da Fundação Getúlio Vargas, com o apoio do Ministério da Cultura. Citam-se algumas criadas nesse país, com propósitos mais específicos, por exemplo, a GNU General Public License (CG-GPL) e GNU Lesser General Public License (CG-LGPL), as quais são adaptações das licenças da F ree Software F oundation para o contexto do C reative Commons. Ambas dão ao programa de computador os direitos básicos do software livre, quais sejam a liberdade de ser executado para qualquer propósito, estudado, adaptado, redistribuído, modificado (Creative Commons, 2001, online). A diferença é que na CG-GPL o programa deve continuar sendo distribuído sob os mesmos termos da licença, enquanto que na CG-LGPL o programa, em algumas circunstâncias poderá ser distribuído sob outros termos. 
Um marco para a utilização do Creative Commons no Brasil foi a Campus Party, um evento ocorrido entre os dias 25 e 31 de janeiro em São Paulo. Mais precisamente no dia 29, Lawrence Lessig e Ronaldo Lemos lançaram a versão 3.0 dessas licenças, adaptando-as ainda mais ao contexto brasileiro. As novidades ficam por conta da reedição das cláusulas relativas aos direitos morais e do rol de definições das licenças, de modo a tornar mais claro e preciso o seu âmbito de atuação, diminuindo as possibilidades de ambiguidade e interpretações adversas (Creative Commons, 2001, on-line).

\subsection{ALGUNS EXEMPLOS DE MODELOS COLABORATIVOS}

Destacam-se as inúmeras possibilidades de aplicação das licenças Creative Commons, por exemplo, livros, noticiários, músicas, blogs, enciclopédias, carros. Sempre com o finco de aumentar os conteúdos de acesso livre, a fluidez da informação contribui não somente para o avanço técnico-científico como, também, para a democratização dos canais de comunicação, consequentemente, proporcionando uma maior possibilidade de efetivação da democracia.

Dentre os grandes projetos engajados no modelo colaborativo, pode-se citar a Wikipédia, uma enciclopédia online cujos autores são seus próprios usuários. Podendo ser editada por qualquer pessoa em qualquer parte do mundo, a Wikipédia está disponível em 268 idiomas ou dialetos, contando com mais de 14 milhões de artigos (Wikipédia, 2001, on-line). Tem seu conteúdo totalmente livre para o acesso, o que permite sua cópia e distribuição para qualquer um que desejar. Cada leitor poderá se tornar um colaborador da enciclopédia, o que acaba por potencializar o projeto, atribuindo-lhe números que dificilmente um projeto regido pelos meios de produção normal chegaria. É o que se vê no Quadro 1, comparando a Wikipédia com outras duas maiores enciclopédias do mundo:

\begin{tabular}{|llll|}
\hline & WKIPÉDIA & BRITANNICA & ENCARTA \\
Verbetes & 7,5 milhões (anglófona) & 28 mil & 28 mil \\
Artigos & 3 milhões (anglófona) & 120 mil & 45 mil \\
Fundação & 15 de Janeiro de 2001 & $\begin{array}{l}1768,(\text { versão on-line } \\
\text { em 2001) }\end{array}$ & 1993 \\
Idiomas & 268 (idiomas e dialetos) & 1 (inglês) & 8 (com limitações) \\
Acesso & Ilimitado, gratuito & Ilimitado, pago & \\
Versões & $\begin{array}{l}\text { On-line e DVD } \\
\text { (edição em alemão) }\end{array}$ & Impressa e on-line & CD-ROM e on-line \\
Revisão & $\begin{array}{l}\text { Instantânea (on-line) } \\
\text { Internautas, especialistas } \\
\text { ou não nos assuntos }\end{array}$ & & Anual. Editores especializados \\
& & & \\
\hline
\end{tabular}

Quadro 1 (F onte: W ikipédia, 2001, online) 
É necessário, no entanto, notar que esse modelo adotado pela Wikipédia também traz alguns pontos negativos, tais como a possibilidade de algum usuário não especializado no assunto criar um conteúdo de maneira imprecisa. Entretanto a Nature, uma renomada revista científica inglesa, em uma pesquisa feita, demonstrou que enquanto a média de erros encontrados por itens na Wikipédia teria uma média de quatro, a de itens on-line da Britannica teria três, o que resultaria num empate técnico (Nature.com, 1995, on-line). Ademais, numa realidade como a brasileira, dificilmente poderia se estabelecer a veracidade das informações produzidas a partir dos modelos provindos do mercado convencional, visto que sempre há por trás uma força de interesses políticos e econômicos.

Uma iniciativa bastante inovadora, no Brasil, é o projeto Fiat Mio, iniciado pela empresa Fiat. Sob o slogan "Um carro para chamar de seu", a ideia é criar um carro colaborativo, todo projetado a partir das licenças Creative Commons. Assim, todos terão acesso ao conteúdo do projeto, podendo utilizá-lo e modificá-lo, inclusive as empresas concorrentes dos ramos de carro. Qualquer pessoa poderá ser participante, seja dando novas ideias ou tomando parte da montagem técnica, bastando apenas entrar no sítio eletrônico do projeto (Fiat Mio, 2009, on-line). O intuito é promover um carro de acordo com a necessidade dos consumidores, possibilitando, assim, uma maior integração entre empresa e cliente.

Vê-se, ainda, a quantidade crescente de livros que passam a ser disponíveis ao público, por meio do Creative Commons, permitindo que seus conteúdos sejam baixados gratuitamente pela internet, utilizados e modificados. A título ilustrativo, menciona-se a obra Direito, Tecnologia e Cultura, do autor Ronaldo Lemos, obra licenciada pela combinação das condições de atribuição, vedados usos comerciais e compartilhamento pela mesma licença (by-nc-sa). Sendo tomada por texto base, é que o presente trabalho a utiliza para criar um texto derivado. Destarte, não é preciso pedir autorização ao autor original, visto que a permissão já é automaticamente concedida quando se recorre ao Creative Commons. O livro poderá ser obtido gratuitamente na internet através do endereço eletrônico http://www.overmundo.com.br/banco/livro-direito-tecnologiae-cultura-ronaldo-lemos.

O governo brasileiro também possui algumas iniciativas nesse campo. O Terra Crime, desenvolvido pela Secretaria Nacional de Segurança Pública em parceria com o Instituto de Tecnologia da Informação da Casa Civil da Presidência da República, é um software livre pela licença CC-GPL. O programa funciona a partir do mapeamento de áreas com incidência criminal, a fim de "embasar não só a repressão policial, mas a formulação e distribuição de programas sociais, rondas policiais e outras abordagens nas estratégias de combate à criminalidade" (Portal Software Livre, on-line).

Enfim, são vários os exemplos que denotam a abrangência do uso do Creative Commons, demonstrando a crescente importância da criação de novos tratamentos à propriedade intelectual, implicando novas relações sociais e de produção. 


\section{CONCLUSÃO}

Com os avanços proporcionados pela internet e pela tecnologia digital, a sociedade contemporânea passou a se deparar com novas transformações, tanto no campo técnico-científico como nas relações sociais. A propriedade intelectual, base da proteção dos direitos autorais, é o instrumento jurídico expressamente previsto na Constituição Federal brasileira (art. $5^{\circ}$, XXVII) que se interliga diretamente com esses avanços, mas que vem se mostrando incapaz de se adaptar aos novos contornos dessa sociedade, na medida em que protege de maneira demasiada os criadores das obras intelectuais em detrimento de outros valores igualmente importantes como a liberdade de expressão e o direito à informação; este é considerado até como direito fundamental de quarta geração, essencial ao funcionamento da democracia moderna.

Nas palavras de Hayek (apud Lemos, 2005, p. 75):

[....] seria interessante descobrir em que medida uma visão crítica realmente séria dos beneficios do direito autoral para a sociedade (...) teria a chance de ser discutida em uma sociedade na qual os canais de expressão encontram-se tão largamente controlados por pessoas que têm um interesse direto na situação existente [....]

Assim, a dificuldade numa nova estruturação dos direitos autorais pode ser superada a partir de iniciativas provindas diretamente da sociedade civil. É aqui onde se apresenta uma alternativa a esse regime: o C reative Commons. O licenciamento público de obras intelectuais dá uma nova visão de organização de produção dessas obras, privilegiando-se um modelo colaborativo, em que todos estão aptos a participar e usufruir igualmente desses bens.

Aconsequênciaimediata desse modeloéa democratização dos canais de comunicação, a qual se mostra, cada vez mais, necessária numa sociedade em que, praticamente, toda a informação é passada na medida da audiência que a mesma pode proporcionar.

Portanto, funcionando como uma maneira de engajamento coletivo, se cada indivíduo se propuser a ficar com apenas alguns direitos reservados, pode-se vislumbrar o nascimento de uma nova sociedade fundada em uma cultura livre, seja de verdades incontestes, seja da privatização do conhecimento; este que é um direito fundamental de todos.

No entanto, ressalta-se que esse novo tipo de licenciamento não pode ser considerado o estágio final de evolução da sociedade no que tange à propriedade intelectual. O Creative Commons ainda é pautado num modelo de produção que abre espaço para o mercado capitalista, principalmente o de conteúdos, como Youtube, Google, MySpace, em que são criadas novas formas de remuneração exclusivas dessas empresas, por exemplo, através da publicidade e ao largo dos autores das obras. Cria-se, então, um conteúdo de livre acesso global, mas, em contrapartida, são fortalecidas as grandes corporações que acabam se tornando verdadeiros monopólios mercadológicos de conteúdos, gerando consequências ainda obscuras. Lembra Paiva (2008): 


\begin{abstract}
Assim, em benefício da livre concorrência, mas em nome da "função social" da "propriedade intelectual", o patrimônio imaterial dos povos deve ser regido por um marco jurídico focado no "acesso equitativo às expressões culturais" e na "abertura às culturas do mundo". Nada disso me é estranho, pois na lógica mais primitiva do capitalismo toda produção só tem sentido se gerar lucro, de preferência lucro fácil, sempre em cima dos elos mais fracos da cadeia socioeconômica.
\end{abstract}

Uma visão mais crítica não pode permitir o vislumbre de uma socialização apenas do conhecimento, enquanto se mantêm os contornos de uma sociedade degradada econômica, ambiental e socialmente. Assim, não há que se encerrar uma luta por uma cultura livre apenas no desfazimento da propriedade intelectual enquanto a propriedade ainda subsiste para manter os mesmos moldes dessa sociedade atual.

"Informação e cultura não chegam aos seus pais

Esse é um problema que vem desde os nossos ancestrais

E o sistema vem manipulando desde sua infância

A melhor maneira de governar o povo

É mantê-lo na ignorância”

(M v Bill, T ipo Racionais)

\title{
REFERÊNCIAS
}

Creative Commons (2001). Disponível em: < http://creativecommons.org.br/> . Acesso em: 25 jan. 2010.

. Disponível em: <http://creativecommons.org/licenses/GPL/2.0/>. Acesso em: 25 jan. 2010.

. Disponível em: <http://www.creativecommons.org.br/index.php?option=com_ content\&task=view\&id=133\&Itemid=1>. Acesso em: 20 fev. 2010.

Fiat Mio (2009) Disponível em: <http://www.fiatmio.cc/pt/sobre-o-projeto/>. Acesso em: 25 jan. 2010.

LEMOS, Ronaldo. Direito, tecnologia e cultura. Rio de Janeiro: FGV, 2005.

Linux Online (1994). Disponível em: <http://www.linux.org/info/>. Acesso em: 25 jan. 2010.

MINISTÉRIO DA GULTURA. Secretaria de políticas culturais. Coordenação-geral de direito autoral. Caderno de Direito Autoral (2009). Disponível em: < http:// www.cultura.gov.br/site/wp-content/uploads/2009/01/livro-direito-autoral.pdf>. Acesso em: 25 jan. 2010. 
Nature.com (1995). Disponível em: <http://www.nature.com/nature/journal/ v440/n7084/full/440582b.html>. Acesso em: 19 fev. 2010.

PAIVA, Flávio. Criativo como, cara pálida? Diário do Nordeste, Fortaleza, Ceará, 04, 11 e 18 dez. 2008 e 08 e 15 jan. 2009. Artigo, Caderno 3, p. 3.

Portal Software Livre. Disponível em: <http://www.softwarelivre.gov.br/noticias/ News_Item.2003-12-16.1515/>. Acesso em: 25 jan. 2010.

Wikipédia (2001). Disponível em: <http://en.wikipedia.org/wiki/Dmca>. Acesso em 19 jan. 2010.

. Disponível em: < http://en.wikipedia.org/wiki/Copyleft>. Acesso em 25 jan. 2010.

. Disponível em: <http://pt.wikipedia.org/wiki/Wikipedia>. Acesso em: 20 jan. 2010.

\section{FREE CULTURE: COLLABORATION AND SHARING}

Abstract: The intellectual property no longer holds the social advances brought by the internet and the digital technology, which are responsible for the development of new social relations. As an alternative to the traditional copyright, there are movements that seek a greater socialization of knowledge. Thus, from the book Direito, tecnologia e cultura, by Ronaldo Lemos, this study aims to outline the movements, especially the so-called Creative Commons, supporting the benefits of a mitigation of intellectual property.

Keywords: Information. Copyright. Free Culture. Creative Commons. 